\title{
Morphological and Molecular Identification of Arbuscular Mycorrhizal (AM) Fungi
}

\author{
Bindu R. Goswami, Manoj V. Parakhia, B.A. Golakiya and Charmy R. Kothari* \\ Department of Biotechnology, Junagadh Agriculture University, Junagadh-362001, India \\ *Corresponding author
}

A B S T R A C T

\section{Keywords}

Arbuscular

Mycorrhizal (AM), Molecular

\section{Article Info}

Accepted:

16 December 2017

Available Online:

10 January 2018

\begin{abstract}
Mycorrhiza is important fungi for agriculture. To study of that plant's root and soil samples were collected from the different regions of junagadh and near to junagadh district. AMF spores were isolated by Wet-sieving-decanting method and AdhesionFlotation Technique. Morphological studies followed by tryphan blue staining revealed different stages with different components of AM fungi in compound microscope. Different size of spores $10 \mathrm{um}, 20 \mathrm{um}, 53 \mathrm{um}$ and $105 \mathrm{um}$ were observed in Scanning Electron Microscope (SEM). DNA of AMF colonized root were extracted by CTAB method. Using universal primers (A) AML1 and AML2 (B) NS 1 and NS 4 have been used for the identification of AM fungi they generated a single clear band around $800 \mathrm{bp}$ and $1100 \mathrm{bp}$. For identification of specific mycorrhizal species Glomus, Aculospora or Gigaspora specific primers ITS1F, ITS4R, GLOM1310F, GLOM5.8R, GIGA5.8R, ARCH1311F, ACAU1660F and LETC1670F used.
\end{abstract}

\section{Introduction}

The impulse that the majority of land plants are dependent on symbiotic microorganisms for growth and survival is now well established, the importance of soil microbes as regulators of plant diversity and abundance are highlighted (van der Heijden et al., 2008). Various symbiotic associations discovered, the one linking roots and fungi - the mycorrhiza is very widespread and is considered to be the determining factor in the evolution of land plants (Pirozynski et al., 1997; Simon et al., 1993). In 2001, the AMF were separated in a new phylum: the Glomeromycota (Schüssler et al., 2001). The Glomeromycota are closely related to the Basidiomycota and the Ascomycota. The taxonomy of the Glomeromycota, classification based on both morphological and Molecular data was only published in 2013 (Redecker et al., 2013). Members of Glomeromycota, AM fungi, are soil-inhabiting fungi characterized by dichotomous branching of their arbuscules located inside the root cortical cells of plants. They form mutualistic symbiotic associations with up to $90 \%$ of vascular plants (Helgason $e t$ al., 1998) and considered to be the ubiquitous symbionts on Earth, for they have been found even under adverse environmental conditions (Bever et al., 2001; Dodd et al., 1996). The taxonomic classification of AMF was 
constructed by grouping the fungal strains based on similarities and differences in their morphological characteristics. Approx. 160 species of AMF have been described by spore morphology according to the International Vesicular Arbuscular Mycorrhiza (INVAM) culture collection (http://invam.caf.wvu.edu/). However, in nature there can be great variation in spore morphology even within an AMF species (Walker and Vestberg, 1998), and many AMF may reproduce only vegetatively without producing spores (Helgason et al., 2002). Several primers targeting the rDNA regions were claimed to be AMF specific. Most of these amplify only a restricted number of glomeromycota or DNA of nontarget organisms. The most comprehensive taxon sampling for the Glomeromycota covers the small subunit (SSU) rDNA (Schüßler et al., 2001a, b), for which a new, AM fungi specific primer pair was published (AML1 and AML2; Lee et al., 2008).

Unlike the often used AM1 primer (Helgason et al., 1998) it is perhaps suitable to amplify sequences from all AMF taxa, but the SSU rDNA is not enough for species resolution of AMF. Molecular analysis provides a way around this obstacle as it has the potential to identify actively growing fungi in field root samples separately for morphological criteria. (Simon et al., 1992; Clapp et al., 1995; Helgason et al., 1998; Rosendahl and Stukenbrock, 2004), because selective PCR amplification depends on the specificity of the primers, there have been several attempts to design primers specific to AMF (Simon et al., 1992; Helgason et al., 1998). Internal transcribed spacer (ITS) sequences have been used for molecular taxonomy (Redecker, 2000; Renker et al., 2006), but they exhibit a high level of variation within AMF species and in single spores (Sanders et al., 1995; Lloyd-Macgilp et al., 1996). Thus, it may be hard to find distinctive features shared by all
AMF, but not found in other organisms Therefore, small subunit rRNA gene was used for AMF-specific primers in this study because it is less variable than ITS, Most of the 214 currently described species (www.amf-phylogeny.com) are characterized only by spore morphology and the majority has not yet been cultured. There is limited variation in morphological characteristics in the spores of these fungi thus creating difficulties in identification and morphotyping, which requires a considerable knowledge of the morphological characteristics of a wide range of different species (Clapp et al., 2001; Tisserant et al., 1998).

\section{Materials and Methods}

\section{Sample collection}

The root and soil samples of some plants were collected from the villages of saurashtra region Junagadh Agriculture UniversityJunagadh, Khijadiya- Visavadar, Mangrol, Sukhpur, Simar, Kidivav, Malia hatina, Malia visanvel, Kukasvada, Shil, Divasa. The soil samples were taken and fine roots were collected in polythene bags from each plant. About 200-300 gm of soil samples from rhizosphere of each plant at a depth of 15$20 \mathrm{~cm}$ was collected in polythene bags with the help of soil augur then brought to laboratory and proceed for isolation of AM fungal spores.

\section{Management of root and soil sample}

Samples were stored at $5-8^{\circ} \mathrm{C}$ to sustain the viability of VAM spores and to lower the microbial activity of the rhizospheric root samples, were not immediately processed in the laboratory. To preserve collected samples, roots were placed in glass tube with formalin acetic acid alcohol (FAA).The standard FAA solution was prepared with $50 \%$ alcohol with a $\mathrm{V} / \mathrm{V} / \mathrm{V}$ ratio of 90:5:5 samples emerged in 
FAA can be kept up to 2.5 years before assay with no adverse effect to the root samples (Brundret et al., 1984).

\section{Microscopy of root}

Rapid clearing and staining technique of Phillip and Hayman (1970) was used for studying mycorrhizal root colonization. Root colonization was determined on replicates stained root segments $1-\mathrm{cm}$ long in a Petri dish, placed in $10 \% \mathrm{KOH}$ at room temperature for 24 hours. Then decant $\mathrm{KOH}$ and root pieces were washed with water until the brown color removed. Then, roots were acidified with $1 \% \mathrm{HCl}$ for 3-5 minutes. Acid was decanted and root pieces were stained with $0.5 \%$ Trypan blue for $24 \mathrm{hrs}$. After that trypan blue was decanted. Identification was based on comparing observed results to published descriptions of previously identified mycorrhiza types in the website http://invam.caf.wvu.edu/fungi/taxonomy/spec ies.ID.htm

\section{Isolation of spore from soil sample}

VAM fungi are oblicate symbiont, they could not isolated from soil by dilution plate method. Gerdemann (1955) first time used successfully wet-sieving and decanting methods for the isolation of VAM fungi. Gerdemann and Nicolson's (1963) wet sieving and decanting procedure was adopted for isolation of VAM spores. Following procedure was used in this experiment.

\section{Wet-sieving and decanting method}

$50 \mathrm{~g}$ of soil were mixed in a convenient volume of water in a large beaker $(500 \mathrm{ml})$ and stirred with a glass rod to make a uniform suspension. The suspension was left for five minutes. In this process, the mycorrhiza spores floated on the top. The suspension was passed through different sieves (Fig. 1) (500, 250,
105, 75 and 50 MIC mesh sizes). This process was repeated 8-9 times to trap all spores of AM fungi. The population of AM fungi was determined. A piece of paper was cut according to the diameter of the Petri dish and grids were made on it. The spores present per $\mathrm{cm} 2$ were counted under compound microscope. Both broken and unbroken spores were observed.

\section{Adhesion-flotation technique}

This method was developed based on their properties of flotation in aqueous solutions and adhesion to glass surfaces.50 gram of soil sample was mixed with $500 \mathrm{ml}$ water and shaked vigorously. The suspension was allowed to settle for 2 minutes and then decanted into $1000 \mathrm{ml}$ separatory funnel (Fig. 2 ). The materials adhering to the inner surface of the separatory funnel was washed down onto filter paper and viewed under dissecting microscope.

A circular filter paper was taken and folded into four equal quadrants. The paper was reopened; two lines were drawn along the two folds to divide the filter paper into four equal quadrants. Vertical lines were drawn on one half of the filter paper so as to divide it into approximately 20 columns about $0.5 \mathrm{~cm}$ apart.

Each column was then numbered and the direction of counting was marked by an arrow. The filter paper was then folded in such a way that the marked portion becomes the receiving surface for the sample during filtration (Fig. 3).

\section{Morphological observation of spores for identification}

Morphology of spores is a basis for identification of AM fungi, because the hyphae and the organs such as arbuscules and vesicles are not specific to species. Spores 
collected from soil often deteriorate so that they may be used only for tentative identification at genus level. Spore from pot culture was used.

\section{Observation of spores under compound microscope}

Spores collected from soil or culturing medium were put in a small Petri dish, for taxonomic identification, fungal spores and sporocarps were mounted onto slides using PVA (polyvinyl alcohol) with and without Melzer's reagent examined with a compound microscope. Their shape, size, colour and bulbous suspensor, sporocarp, surface ornamentation, vesicles etc were recorded. Spores were classified into each spore type based upon morphology. For each spore type, detailed observation is conducted. morphotypes were selected and observed under a Zeiss compound microscope.

\section{Scanning electron microscopy (SEM) of AMF spores}

The study was conducted at Department of Biotechnology Junagadh Agriculture University. The Spore sample of VAM fungi was covered separately with fixative solution (4\% glutaraldehyde) for $12-24 \mathrm{~h}$ at $4^{\circ} \mathrm{C}$. The samples were washed with $0.1 \mathrm{M}$ sodium cacodylate buffer for 3 changes of 30 min for each change. $1 \%$ Osmium tetroxide was used for post fixation for $2 \mathrm{~h}$ at $4^{\circ} \mathrm{C}$. The samples were washed again with $0.1 \mathrm{M}$ sodium cacodylate buffer for 3 changes of $30 \mathrm{~min}$ each change. For dehydration process, samples were placed in $35 \%$ acetone for 30 min, followed by $50 \%$, for $30 \mathrm{~min}, 75 \%$ for 30 min, $95 \%$ acetone for $30 \mathrm{~min}$ and finally 3 changes of $100 \%$ acetone at $1 \mathrm{hr}$ interval. The specimens were staked onto stab using colloidal silver. The specimens were coated by gold in sputter coater machine and it was viewed using scanning electron microscope (ZEISS-EVO-18).

\section{Extraction of DNA from root sample}

One gram sample of test root was weighed and ground with liquid nitrogen so as to keep the tissue frozen. The powdered sample was immediately transferred to a tube that was having pre-warmed extraction buffer $(7 \mathrm{ml})$. These samples were incubated at $65^{\circ} \mathrm{C}$ for 2 hr. After incubation, the above solution was allowed to cool at room temperature for 15-20 minute. Chloroform and isoamyl alcohol solution (24:1) was added to this solution to denatured protein. Centrifuged at 20,000 rpm for $15-20 \mathrm{~min}$ at $4^{0} \mathrm{C}$. After centrifugation, the upper phase was transferred to a new tube.

To this upper phase, pre chilled i.e., $4000 \mu \mathrm{l}$ isopropanol was added and mixed properly by tapping. It was kept overnight in ice. The solution was again centrifuged at $15,000 \mathrm{rpm}$ for $20 \mathrm{~min}$ at $4^{0} \mathrm{C}$. Supernatant was poured off and DNA was collected. DNA pellet was washed with 70 per cent ethanol $(4 \mathrm{ml})$ and centrifuged at $10,000 \mathrm{rpm}$ for $10-15 \mathrm{~min}$ at $4^{0} \mathrm{C}$. Supernatant was discarded and DNA pellet was dried in vacuum oven for 15-20 minute. DNA pellet was kept overnight. It was then dissolved in $500 \mu \mathrm{l}$ of sterilized water or TE buffer.

\section{Agarose gel electrophoresis for DNA}

$0.8 \%$ of agarose gel (w/v) was prepared using $1 \mathrm{X}$ TE buffer by metling in a heating mantle and cooling at $60^{\circ} \mathrm{C}$. After cooling add one to two drop of ethidium bromide. Each DNA sample was taken and mixed with 6X gel loading dye $(0.25 \%$ Bromophenol blue). Then the above mixture was loaded into separate well with the help of micropipette. The DNA marker was loaded for comparison. The lid of the gel tank was closed. The power supply was connected to run the electrophoresis (Agarose gels should be not run more than 5 $\mathrm{v} / \mathrm{cm}$. After the run was completed gel was scanned under UV visible light. 


\section{PCR protocol}

Fragments of the nuclear ribosomal small subunit were amplified by PCR from DNA of root sample with the set of universal primers AML1 (5'ATC AAC TTT CGA TGG TAG GAT AGA-3') and AML2 (5'GAA CCC AAA CAC TTT GGT TTC C-3') and NS1(5'GTA GTC ATA TGC TTG TCT C-3') to NS4 (5'CTT CCG TCA ATT CCT TTA AG-3')(White et al., 1990).Cycling parameter was $3 \mathrm{~min}$ at $95^{\circ} \mathrm{C}, 20 \mathrm{~s}$ at $94^{\circ} \mathrm{C}, 35 \mathrm{~s}$ at $55^{\circ} \mathrm{C}, 1 \mathrm{~min}$ at $72^{\circ} \mathrm{C}$ and $72^{\circ} \mathrm{C}$ for $5 \mathrm{~min}$ for 40 cycles The reaction mixture consist of $1.5 \mu 1$ each nucleotide, $3 \mu \mathrm{l}$ each of primers, $0.4 \mathrm{u} / \mu \mathrm{l}$ Taq polymerase, and the reaction buffer $3 \mu$ l. Specificity of primers was tested as follows. Reaction mixture was diluted 1:1,000 or $1: 10,000$ for exceptionally strong bands. These dilutions were then used as template for the second PCR step.

\section{Second step PCR principle}

Second PCR to increase specificity of amplification reaction by performing two step PCR reactions one after another.

\section{Procedure}

The second step was conducted with various combinations of Glomales-specific primers, universal primers (White et al., 1990) ITS1F (CTT GGT CAT TTA GAG GAA GTA A) and ITS4R (CAG ACT T(G/A)TA(C/T)ATG GTC CAG) Annealing temperatures were 54 to $60^{\circ} \mathrm{C}$ for 35 cycles. In specificity tests, templates were tested with universal primers ITS1F and ITS4R to verify amplifiability. Specific primers were combined in three sets in the second amplification step to minimize the number of PCR reactions. Set 1 contain GLOM 1310F (AGC TAG GYC TAA CAT TGT TA) and GLOM 5.8R (TCC GTT GTT GAA AGT GAT C), set 2 contained the reverse specific primers (GLOM5.8R, GIGA5.8R (ACT GAC CCT CAA GCA K
GTG)) in combination with ITS1F. Set 3 contained the forward specific primers ARCH1311F (TGC TAA ATA GCC AGC CTG Y), ACAU1660F (TGA GAC TCG GAT CGG), LETC1670F (GAT CGG CGA TCG GTG AGT) combined with ITS4R.

\section{Results and Discussion}

Rhizosperic soil sample from different locations of Saurashtra were subjected to the recovery of AM fungal spores. The soil samples of different location showed different types of spores. All the recovered spores represent six genera. Acaulospora, Gigaspora, Sclerocystis, Scutellispora, Glomus and Entrophospora. The entire collected rhizospere sample exhibited the presence of varied range of spore population in the soil profile.

\section{Morphological study}

Morphological studies followed by tryphan blue staining revealed different stages with different components of AM fungi. Microscopic measurements provided an assessment of the relative abundance of mycelium in root, hyphae within root, entry points and pattern of outer epidermal cells. Arbuscules of various stages of the growth were observed and some were in the state of disintegration. arbuscular branches were long or short, deteriorating and collapsing. Vesicles size and shape diffused depending on the anatomy of the root, varying in size (Table 2, Fig. 4 and 5).

\section{Scanning electron microscopy (SEM)}

SEM of isolated spore was done at lab of DBT of Junagadh Agriculture University. Different size of spores were $10 \mathrm{um}, 20 \mathrm{um}, 53 \mathrm{um}$ and 105 um observed. Figure 6 showing funnel shaped subtending hyphae attached to a globose or subglobose spore. 
Fig.1 Soil suspention and sieve (500, 250, 105, 75 and 50 MIC mesh sizes)

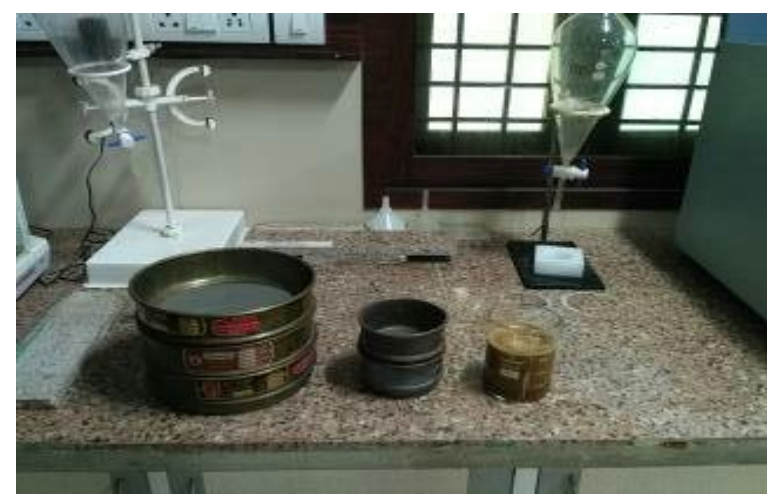

Fig.2 Soil suspension in separation funnel

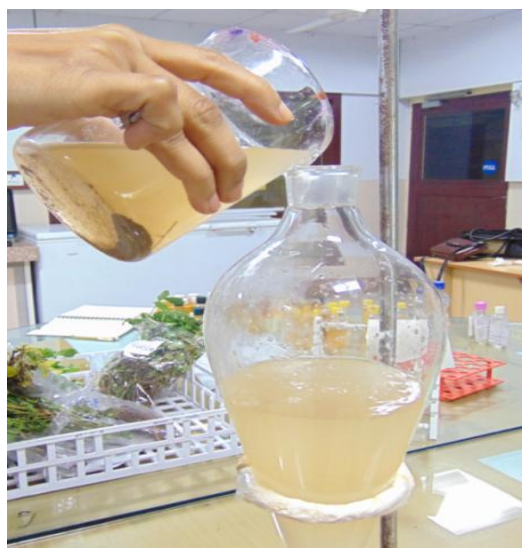

Fig.3 filter paper containing AMF spores

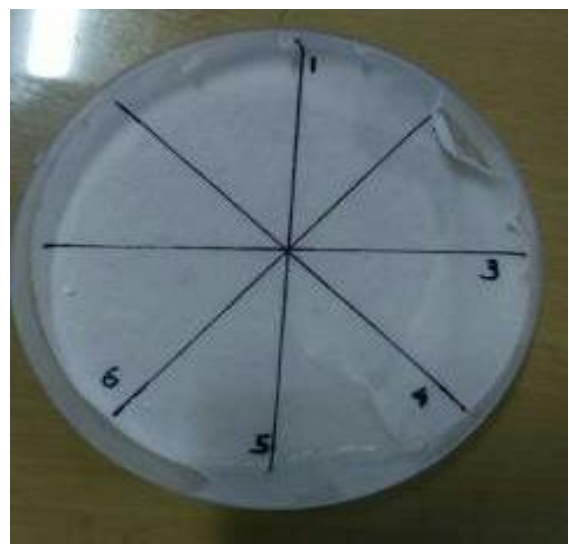

Fig.4 Microscopy of AMF containing colonized root
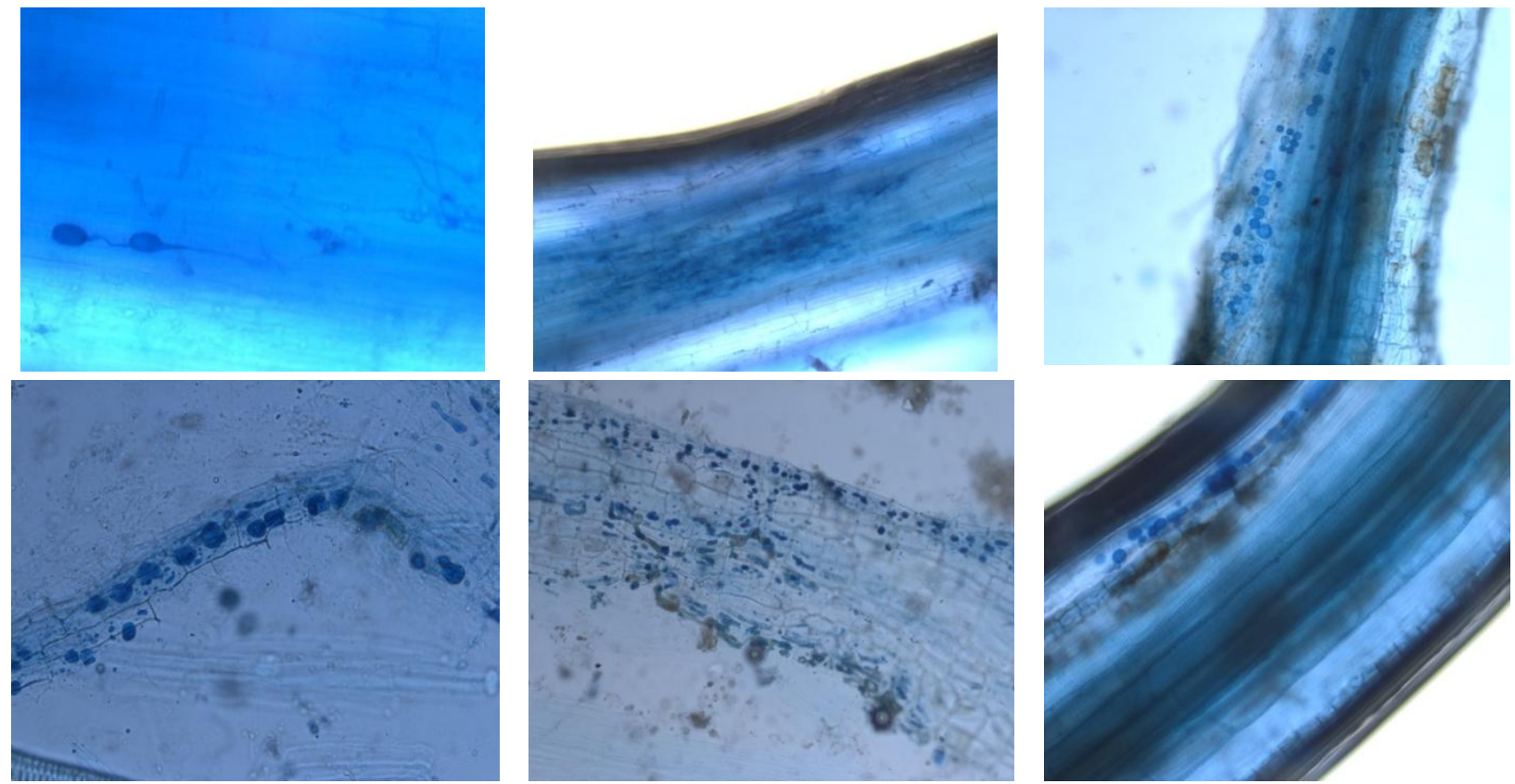
Int.J.Curr.Microbiol.App.Sci (2018) 7(1): 2336-2347
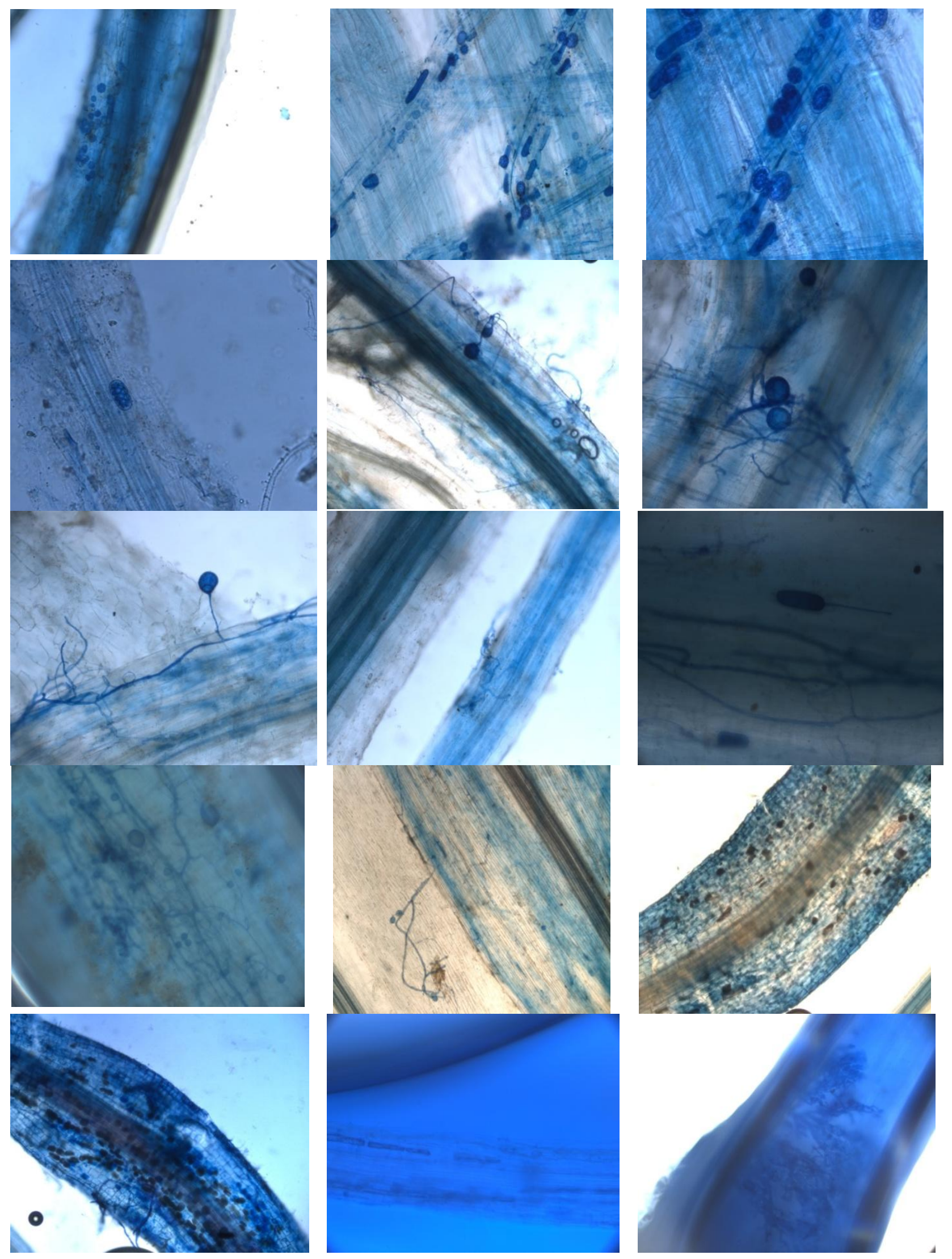
Int.J.Curr.Microbiol.App.Sci (2018) 7(1): 2336-2347
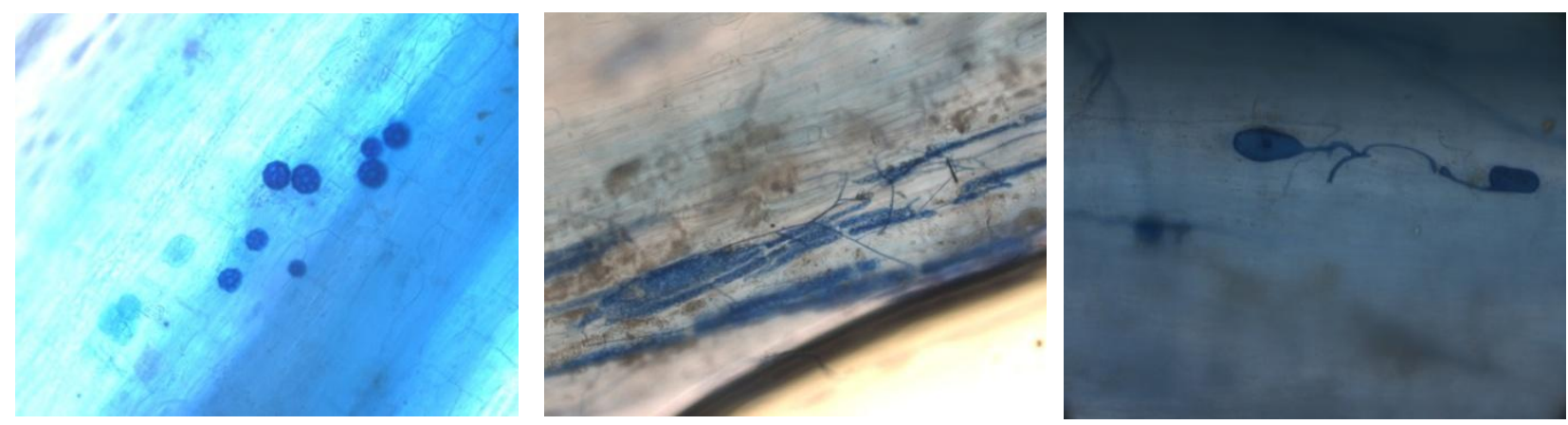

Fig.5 Isolated AMF Spore from the soil sample

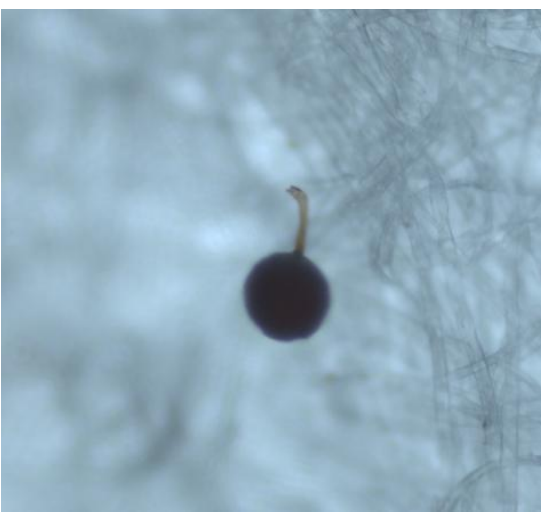

Spore of genus Glomus

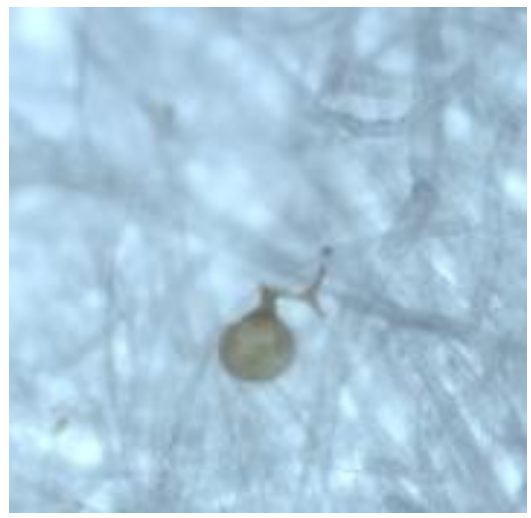

Spore of genus Gigaspora
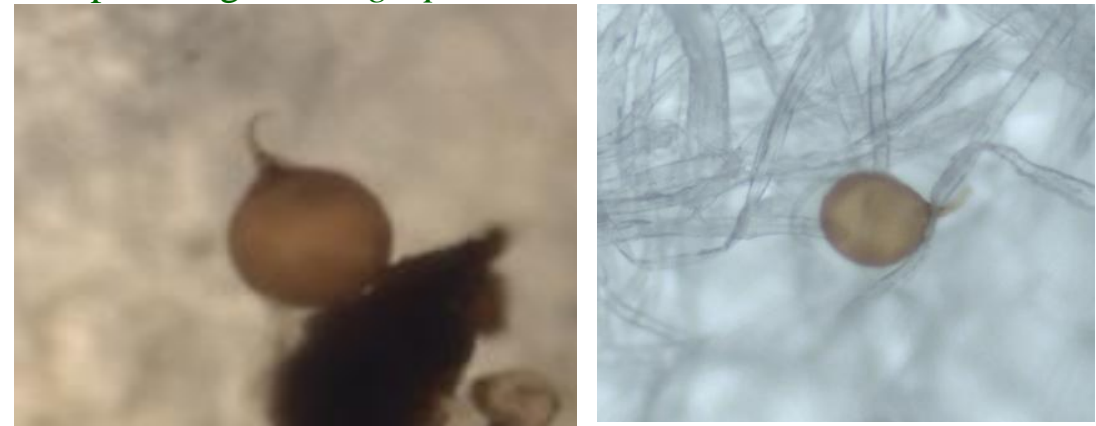

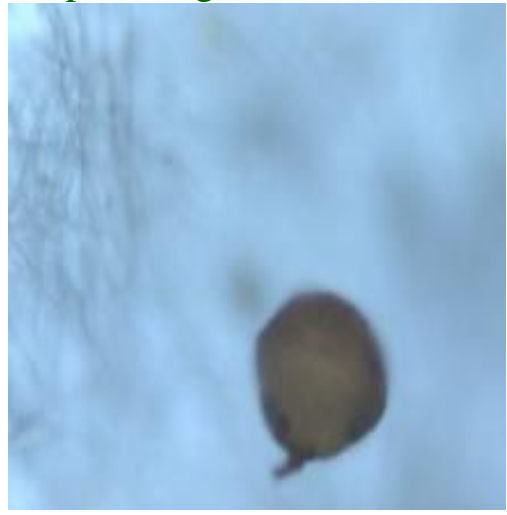

Spore of genus Aculospora
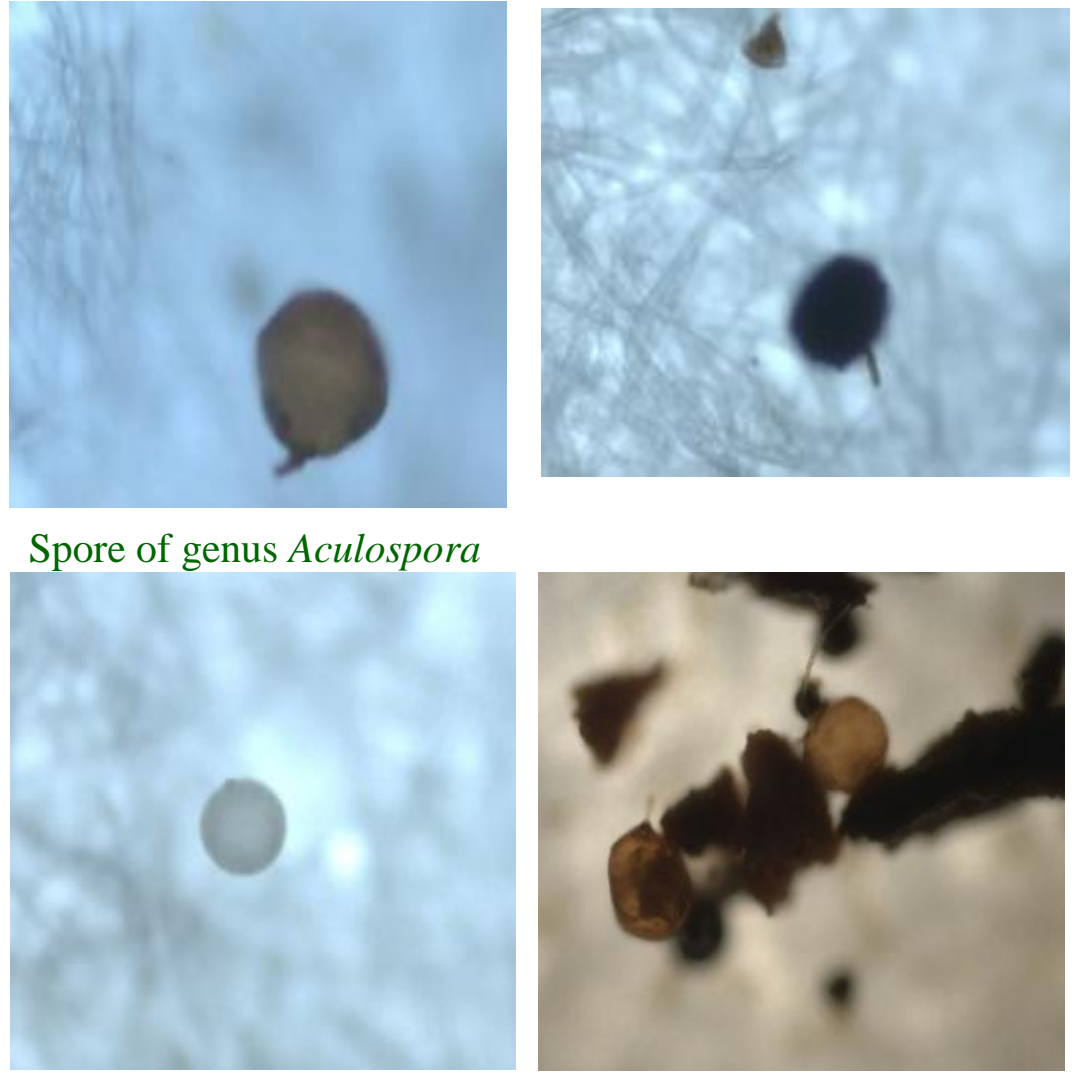
Fig.6 SEM image of AMF spore

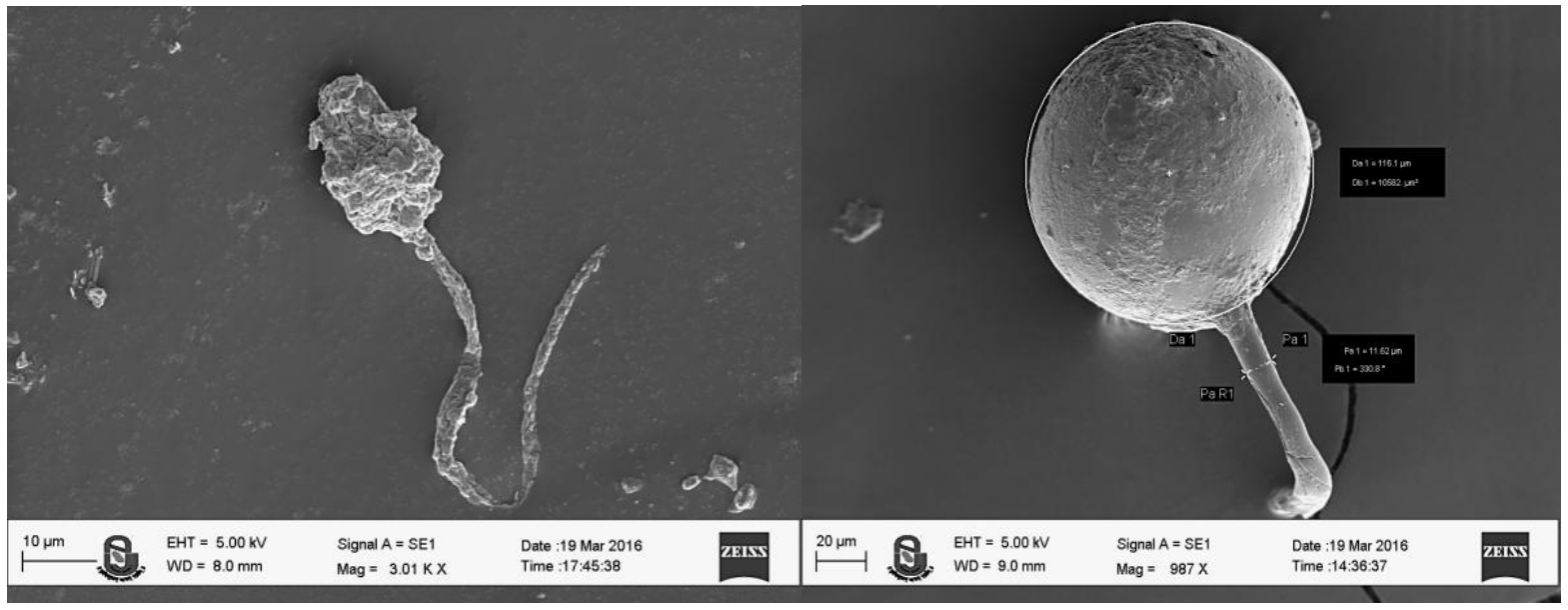

Fig.7 PCR amplification with universal primers (A) NS1 and NS4 (800 bp) (B) AML1 and AML2 (1100 bp)

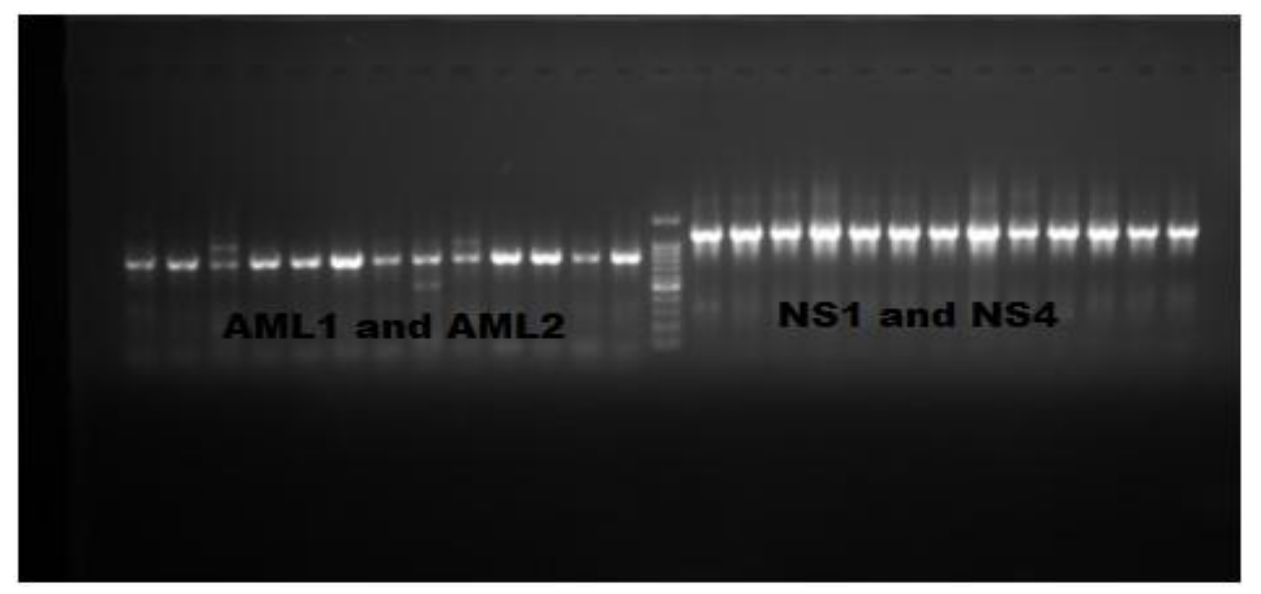

Fig.8 Amplification with Genus specific AMF primers (1) GLOM 1310F -GLOM 5.8R (2) GLOM5.8R -ITS 1F, (3) GIGA5.8R- ITS1F, (4) ARCH1311F-ITS4R., (5) ACAU1660F ITS4R, (6) LETC1670F- ITS4R

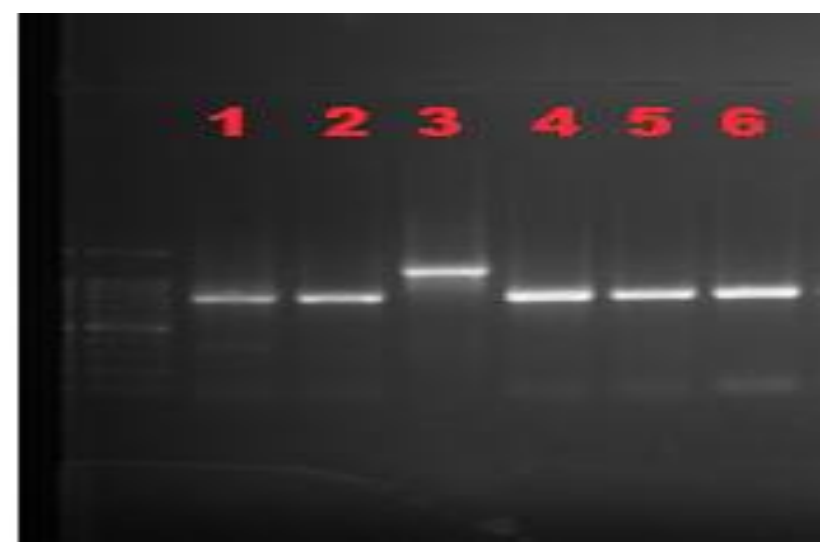


Table.1 Primer used for the amplification of AMF

\begin{tabular}{lll}
\hline Sr.no. & Primer & \multicolumn{1}{c}{ Sequence $\left(5^{\prime} \rightarrow 3^{\prime}\right)$} \\
\hline 1 & AML1 & ATC AAC TTT CGA TGG TAG GAT AGA \\
2 & AML2 & GAA CCC AAA CAC TTT GGT TTC C \\
3 & NS1 & GTA GTC ATA TGC TTG TCT C \\
4 & NS4 & CTT CCG TCA ATT CCT TTA AG \\
5 & ITS1F & CTT GGT CAT TTA GAG GAA GTA A \\
6 & ITS4R & CAG ACT T(G/A)TA(C/T)ATG GTC CAG \\
7 & GLOM 1310F & AGC TAG GYC TAA CAT TGT TA \\
8 & GLOM 5.8R & TCC GTT GTT GAA AGT GAT C \\
9 & ARCH1311F & TGC TAA ATA GCC AGC CTG Y \\
10 & ACAU1660F & TGA GAC TCG GAT CGG \\
11 & LETC1670F & GAT CGG CGA TCG GTG AGT \\
\hline
\end{tabular}

Table.2 Morphological features of spore

Family

Glomus

Acaulospora

Gigaspora

\section{Spore color}

Black, Red brown and yellow brown

Dark brown, yellow brown

White and cream

\section{Spore shape}

Globose to ellipsoid

Globose to sub globose

Globose to sub globose

\section{Hyphe color}

Hyaline, yellowish

Grey white

Orange brown
The point of attachment at the base was wide and tapper towards the end assuming a typical funnel shape.

\section{Isolation of DNA from root samples}

In the isolation and purification of DNA, CTAB method was found to be good for successful isolation. DNA was isolated from root sample of different plants. The DNA obtained was reasonably of good quantity and quality. Further purification was done by RNase treatment followed by phenol: chloroform extraction and re-precipitation by ethanol (100\%) was done. DNA will be used for further experiments in future of PCR (polymerase chain reaction) amplification analysis.

\section{PCR}

Universal primers (A) AML1 and AML2 (B)NS 1 and NS 4 has been used for the identification of AM fungi.AML1 and AML2 generated a single clear PCR product of around $800 \mathrm{bp}$ from colonized roots.NS1 and NS4 generated a 1100 bp clear band(Fig. 7). DNA ladder was used for comparison. Sequences of all products fell within the phylum glomeromycota. A set of PCR primers were used for amplification. Combination of the primers were in set were found to be useful approach to screen root samples for the presence of AM fungi. ITS sequences were used for molecular taxonomy and it exhibits a high level of variation within AMF species. The first PCR product was 
diluted1/100 with TE buffer. The first PCR product was used as a template DNA in a second PCR reaction performed using new primer set (Fig. 8 and Table 1).

\section{Acknowledgement}

The authors are thankful to Dr. B.A. Golakiya, Department of Biotechnology, Junagadh Agriculture University of Junagadh for providing laboratory facilities.

\section{References}

Bever JD, Schultz PA, Pringle A, Morton JB. 2001. Arbuscular mycorrhizal fungi: More diverse than meets the eye, and the ecological tale of why. Bioscience 51: 923-931

Brundrett, M.C., Piche, Y. and Peterson, R.L. 1984. A new method for observing the morphology of vesicular-arbuscular mycorrhizae. Canadian Journal of Botany-Revue Canadienne de Botanique, 62, 2128-2134.

Clapp, J.P., Rodriguez, A., and Dodd, J.C. 2001. Inter- and intra-isolate rRNA large subunit variation in Glomus coronatum spores. New Phytologist 149: 539-554

Clapp, J.P., Young, J.P.W., Merryweather, J.W., and Fitter, A.H. 1995. Diversity of fungal symbionts in arbuscular mycorrhizas from a natural community. New Phytologist 130: 259-265.

Dodd J.C., Rosendahl S., Giovannetti M., Broome A., Lanfranco L. and Walker C. 1996. Inter- and intraspecific variation within the morphologically-similar arbuscular mycorrhizal fungi Glomus mosseae and Glomus coronatum. New Phytol. 133: 113-122.

Gerdemann, J.W. 1955. Relation of a large soil-borne spore to phycomycetous mycorrhizal infection. Mycologia. 47:619-632.
Gerdemann, J.W., and Nicolson, T.H. 1963. Spores of mycorrhizal Endogone species extracted from soil by wet sieving and decanting. Transactions of the British Mycological Society 46: 235244.

Helgason, T., Daniell, T.J., Husband, R., Fitter, A.H., and Young, J.P.W. 1998. Ploughing up the wood-wide web? Nature 394: 431-431.

Helgason, T., Merryweather, J.W., Denison, J., Wilson, P., Young, J.P.W., and Fitter, A.H. 2002. Selectivity and functional diversity in arbuscular mycorrhizas of co-occurring fungi andplants from a temperate deciduous woodland. Journal of Ecology 90: 371384.

http://invam.caf.wvu.edu/

Lee J, Lee S, Young JP+W. 2008. Improved PCR primers for the detection and identification of arbuscular mycorrhizal fungi. FEMS Microbiology Ecology 65: 339-349

Lloyd MacGilp, S.A., Chambers, S.M., Dodd, J.C., Fitter, A.H., Walker, C., and Young, J.P.W. 1996. Diversity of the ribosomal internal transcribed spacers within and among 173 isolates of Glomus mosseae and related mycorrhizal fungi. New Phytologist 133: 103- 111.

Phillips, J.M., and Hayman, D.S. 1970. Improved procedures for clearing roots and staining parasitic and vesiculararbuscular mycorrhizal fungi for rapid assessment of infection. Transactions of the British Mycological Society 55: 158161.

Pirozynski KA, Malloch DW. The origin of land plants: a matter of mycotrophism. Biosystems. 1975; 6: 153-164.

Redecker, D., 2000. Specific PGR primers to identify arbuscular mycorrhizal fungi within colonized roots. Mycorrhiza 10: 73-80. 
Redecker, D., Schüßler, A., Stockinger, H., Stürmer, S., Morton, J., and Walker, C. 2013. An evidence-based consensus for the classification of arbuscular mycorrhizal fungi (Glomeromycota). Mycorrhiza 23: 515-531.

Renker C, Weisshuhn K, Kellner $\mathrm{H}$ and Buscot F 2006. Rationalizing molecular analysis of field-collected roots for assessing diversity of arbuscular mycorrhizal fungi: to pool, or not to pool, that is the question. Mycorrhiza 16: 525-531.

Rosendahl S and Stukenbrock E 2004. Community structure of arbuscular mycorrhizal fungi in undisturbed vegetation revealed by analyses of LSU rDNA sequences. Mol Ecol 13: 31793186.

Sanders IR, Alt M, Groppe K, Boller T and Wiemken A 1995. Identification of ribosomal DNA polymorphisms among and within spores of the Glomales: application to studies on the genetic diversity of arbuscular mycorrhizal fungal communities. New Phytol 130: 419-427.

Schüßler A, Gehrig H, Schwarzott D, Walker C. 2001a. Analysis of partial Glomales SSU rRNA gene sequences: implications for primer design and phylogeny. Mycological Research 105: 5-15.

Schüßler A, Schwarzott D, Walker C. 2001b. A new fungal phylum, the Glomeromycota: phylogeny and evolution. Mycological Research 105:
1413-1421.

Schussler, A., Schwarzott, D., and Walker, C. 2001. A new fungal phylum, the Glomeromycota: phylogeny and evolution. Mycological Research 105: 1413-1421.

Simon L, Bousquet J, Lévesque RC, Lalonde M. Origin and diversification of endomycorrhizal fungi and co-incidence with vascular land plants. Nature. 1993; 363: 67-69.

Simon L, Lalonde M and Bruns TD 1992. Specific amplification of $18 \mathrm{~S}$ fungal ribosomal genes from vesiculararbuscular endomycorrhizal fungi colonizing roots. Appl Environ Microbiol 58: 291-295.

Tisserant, B., Brenac, V., Requena, N., Jeffries, P., and Dodd, J.C. 1998. The detection of Glomus spp. (arbuscular mycorrhizal fungi) forming mycorrhizas in three plants, at different stages of seedling development, using mycorrhiza-specific isozymes. New Phytologist 138: 225-239.

Van der Heijden MG, Bardgett RD, van Straalen NM. The unseen majority: soil microbes as drivers of plant diversity and productivity in terrestrial ecosystems. Ecol Lett. 2008; 11: 296310.

Walker C, Vestberg M. 1998. Synonymy amongst the arbuscular mycorrhizal fungi: Glomus claroideum, G. maculosum, G. multisubstensum and G. ®stulosum. 1998. Annals of Botany82: $601 \pm 624$.

\section{How to cite this article:}

Bindu R. Goswami, Manoj V. Parakhia, B.A. Golakiya and Charmy R. Kothari. 2018. Morphological and Molecular Identification of Arbuscular Mycorrhizal (AM) Fungi. Int.J.Curr.Microbiol.App.Sci. 7(01): 2336-2347. doi: https://doi.org/10.20546/ijcmas.2018.701.282 